\title{
Effects of oocyte culture density on meiotic competence of canine oocytes
}

\author{
T. Otoi ${ }^{1,2}$, L. Willingham ${ }^{1}$, T. Shin ${ }^{1}$, D. C. Kraemer ${ }^{1}$ \\ and $M$. Westhusin ${ }^{1}$ \\ ${ }^{1}$ Department of Physiology and Pharmacology, College of Veterinary Medicine Texas A\&M \\ University, College Station, TX 77843-4466, USA; and ${ }^{2}$ Laboratory of Animal Reproduction \\ and Biotechnology, Department of Veterinary Sciences, Yamaguchi University, Yamaguchi \\ 753-8515, Japan
}

\begin{abstract}
This study was conducted to determine a suitable ratio of oocytes to medium for in vitro maturation (IVM) of cumulus-oocyte complexes (COCs) collected from bitches at anoestrus and dioestrus and to examine the meiotic competence of COCs cultured singly or in different group sizes. In the first experiment, different numbers of COCs $(5,10,15$ and 20 per drop) were cultured for $72 \mathrm{~h}$ in $100 \mu \mathrm{l}$ drops of maturation medium. The meiotic competence of oocytes from ovaries at anoestrus was affected by the number of COCs incubated, whereas at dioestrus, the incubation number of COCs had no effect. In the second experiment, COCs were cultured singly or in different group sizes for $72 \mathrm{~h}$ by suitable oocyte density according to the reproductive cycle of the donor. In the
\end{abstract}

anoestrous group, 1, 5 and 10 COCs were cultured in 10, 50 and $100 \mu \mathrm{l}$ drops of the medium (10 $\mu$ l per COC), respectively. In the dioestrous group, 1, 5 and 15 COCs were cultured in 7, 35 and $105 \mu \mathrm{l}$ drops of the medium ( $7 \mu \mathrm{l}$ per COC), respectively. There were no differences in the proportions of oocytes reaching metaphase II among the different group sizes in each stage of the reproductive cycle of the donor. The results indicate that the influence of oocyte density on the meiotic competence of oocytes differs according to the stage of the reproductive cycle of the donor. Moreover, the group sizes have no effect on the meiotic competence of oocytes cultured at suitable oocyte density according to the reproductive cycle of the donor.

\section{Introduction}

Successful maturation, fertilization and embryo development in vitro is a prerequisite for the techniques required for assisted reproduction of endangered canine species. Although studies have examined the feasibility of in vitro maturation (IVM) of canine oocytes (Yamada et al., 1992; Nickson et al., 1993; Hewitt and England, 1997; Otoi et al., 2000a), the rates of maturation of oocytes to metaphase II still remain low $(<40 \%)$. Therefore, the low meiotic competence of canine oocytes cultured in vitro is a major obstacle to the in vitro production of embryos. Oocytes used for IVM in the dog are usually obtained from deeper cortical follicles by slicing ovaries, to increase the number of oocytes recovered from canine ovaries. The rates of meiotic completion of canine oocytes have varied, because the oocytes used for IVM experiments have been collected from different sources, and cultured by a variety of different culture systems and media (Farstad, 2000). The age of the donor bitch (Hewitt and England, 1998), oestrous cycle stage of the donor (Yamada et al., 1993; Otoi et al., 2001) and oocyte diameter (Hewitt and England, 1998; Otoi et al., 2000a) influence the IVM rates of the oocytes collected from ovaries obtained by ovariohysterectomy. In most

Email: otoi@qube.agr.yamaguchi-u.ac.jp studies, canine oocytes have been cultured using adaptations of bovine and pig IVM techniques. Studies in other species (mice, hamsters and cows) showed that the volume of medium and oocyte or embryo density (number per unit volume) are important factors that influence IVM, in vitro fertilization and embryo development (Kato and Tsunoda, 1994; Carolan et al., 1996; Kito et al., 1997).

However, in studies of IVM on canine oocytes, oocytes have been cultured in various volumes of medium and at various oocyte densities that may influence IVM rates of the oocytes (Mahi and Yanagimachi, 1976; Yamada et al., 1993; Hewitt et al., 1998; Fujii et al., 2000).

Nickson et al. (1993) reported that the morphological quality of oocytes affects the IVM rates of canine oocytes. They suggested that only oocytes with at least two layers of cumulus cells reached metaphase II. Although a large number of oocytes can be collected from the ovarian tissue of bitches, the proportions of good quality oocytes with at least two layers of cumulus cells from individual ovaries vary greatly from $0 \%$ to $50 \%$ (Nickson et al., 1993; Fujii et al., 2000). Thus, canine oocytes need to be cultured singly or in small groups for IVM and subsequent culture.

The reproductive biology of bitches is unique. The bitch is monoestrous, and has a 2 month luteal phase and a prolonged, but variable, non-seasonal anoestrus of 3-10 months at the end of both pregnant and non-pregnant 
cycles. The ovaries obtained by ovariohysterectomy in veterinary clinics are mainly at anoestrus or dioestrus, in which follicles on the surface of the ovary are not visible. It has been demonstrated that the meiotic competence of oocytes collected from ovaries of bitches at oestrus is significantly higher than that of oocytes at anoestrus and dioestrus (Yamada et al., 1993; Hewitt and England, 1997). Therefore, improvement of meiotic competence of oocytes from anoestrus and dioestrus has been required for in vitro embryo production.

The objectives of the present study were to examine a suitable ratio of oocyte to medium for IVM of canine oocytes collected from ovaries at two stages of the oestrous cycle (anoestrus and dioestrus), and to investigate the effect of culturing oocytes singly or in small groups on the meiotic competence of oocytes.

\section{Materials and Methods}

\section{Oocyte preparation}

Ovaries were collected from bitches by ovariohysterectomy following anaesthesia at local veterinary practices. The animals were of various breeds and ranged in age from 6 months to 3 years. Both ovaries from each bitch were brought to the laboratory in physiological saline $(0.85 \%$ $(\mathrm{w} / \mathrm{v}) \mathrm{NaCl}$ ) at $30^{\circ} \mathrm{C}$ within $6 \mathrm{~h}$ of removal. Bitches were categorized according to the stage of oestrous cycle by the examination of morphology of reproductive tissue: specific morphological criteria were used to identify these stages according to the study of Hewitt et al. (1998). The reproductive status of the donors was categorized as: (1) anoestrous, ovaries without follicles or pronounced luteal tissues; (2) oestrous (follicular phase), one or more visible follicles (2-10 mm in diameter) were present; and (3) dioestrous, one or more pronounced corpora lutea were present. Only ovaries at anoestrus (33 pairs) and dioestrus (46 pairs) were used for this study. The ovaries were placed in TCM-199 medium (Hank's salts) buffered with 25 mmol Hepes buffer $\mathrm{I}^{-1}$ (Gibco, Grand Island, NY) supplemented with $50 \mu$ g gentamicin $\mathrm{ml}^{-1}$ (Sigma, St Louis, MO) at $37^{\circ} \mathrm{C}$, and then sliced repeatedly to release oocytes. Only nondegenerate cumulus-oocyte complexes (two or more dense layers of cumulus cells and darkly granulated cytoplasm) were collected and suspended in culture medium (TCM-199 medium (Earle's salts) buffered with $25 \mathrm{mmol}$ Hepes buffer $\mathrm{I}^{-1}$ supplemented with $10 \%(\mathrm{v} / \mathrm{v})$ bitch serum, and $50 \mu \mathrm{g}$ gentamicin $\mathrm{ml}^{-1}$ ). The bitch serum used for culture was collected from healthy bitches at the time of ovariohysterectomy and was heat-inactivated for $30 \mathrm{~min}$ at $56^{\circ} \mathrm{C}$ and stored at $-30^{\circ} \mathrm{C}$ until it was used. The concentrations of progesterone and oestradiol of the heat-inactivated serum were $1.6 \mathrm{ng} \mathrm{ml}^{-1}$ and $31.5 \mathrm{pg} \mathrm{ml}^{-1}$, respectively. The concentrations were measured using a luminescence-enhanced immunoassay system (Immulite; Diagnostic Products Co., Los Angeles, CA).

The vitelline diameter of the cumulus-oocyte complexes
(COCs) from ovaries at anoestrus and dioestrus was measured using a calibrated ocular micrometer (OSM-4; Olympus, Tokyo), and the oocytes were divided into two groups according to their diameter: $<110$ and $>110 \mu \mathrm{m}$. Only oocytes with diameter $>110 \mu \mathrm{m}$ were selected and used for this study because oocytes of this size have greater potential for maturation than those with diameter $<110 \mu \mathrm{m}$ (Theiss, 1997).

\section{Oocyte culture}

In the first experiment, the effect on IVM rates of the number of COCs incubated and collected from ovaries at each stage of the oestrous cycle was tested. Different numbers of COCs (5, 10, 15 and 20 per drop) were transferred into $100 \mu \mathrm{l}$ drops (four drops per dish) covered with warm paraffin oil $(3.5 \mathrm{ml}$, Sigma) in a polystyrene culture dish $(35 \mathrm{~mm} \times 10 \mathrm{~mm}$; Falcon; Becton Dickinson Labware, NJ), which had been equilibrated in a $\mathrm{CO}_{2}$ incubator at $38.5^{\circ} \mathrm{C}$ for $2 \mathrm{~h}$. Subsequently, the COCs were cultured for $72 \mathrm{~h}$ at $38.5^{\circ} \mathrm{C}$ in a humidified atmosphere of $5 \% \mathrm{CO}_{2}$ in air.

In the second experiment, the effect of culturing COCs singly or in different group sizes on IVM rates was tested. As the suitable number of COCs to a $100 \mu$ drop was found to differ at different stages of the oestrous cycle of ovary in the first experiment, different volumes of culture medium to a COC were used in this second experiment. In the anoestrous group, 1, 5 and 10 COCs were incubated in $10 \mu \mathrm{l}$ drops (ten drops per dish), $50 \mu \mathrm{l}$ drops (two drops per dish) and $100 \mu \mathrm{l}$ drops (one drop per dish) respectively, and covered with paraffin oil $(3.5 \mathrm{ml})$ in a polystyrene dish. The volume of culture medium to a COC was $10 \mu \mathrm{l}$. In the dioestrous group, 1, 5 and 15 COCs were placed in $7 \mu \mathrm{l}$ drops (15 drops per dish), $35 \mu$ drops (three drops per dish) and $105 \mu \mathrm{l}$ drops (one drop per dish) covered with paraffin oil $(3.5 \mathrm{ml})$ in a polystyrene culture dish. The volume of culture medium to a COC was $7 \mu \mathrm{l}$. In each group, the ratio of volume of mineral oil to total volume of culture medium in a dish was the same between experimental treatments because the mineral oil may absorb oestradiol in culture medium (Funahashi et al., 1994). These COCs were cultured for $72 \mathrm{~h}$ at $38.5^{\circ} \mathrm{C}$ in a humidified atmosphere of $5 \% \mathrm{CO}_{2}$ in air.

\section{Oocyte fixing and staining}

After incubation for $72 \mathrm{~h}$, the COCs were transferred into TCM-199 medium (Hank's salts) buffered with 25 mmol Hepes buffer $\mathrm{I}^{-1}$ supplemented with $0.3 \%(\mathrm{w} / \mathrm{v})$ hyaluronidase (Sigma) and then vortexed for $5 \mathrm{~min}$ to remove cumulus cells. After vortexing, the remaining cumulus cells surrounding oocytes were removed using small glass pipettes. Denuded oocytes were fixed and permeabilized for $15 \mathrm{~min}$ at room temperature in Dulbecco's phosphate-buffered saline (PBS; Gibco) supplemented with $3.7 \%(\mathrm{w} / \mathrm{v})$ paraformaldehyde and $1 \%(\mathrm{v} / \mathrm{v})$ Triton-X100 (Sigma), and then placed in PBS containing $0.3 \%(\mathrm{w} / \mathrm{v})$ polyvinylpyrrolidone for $15 \mathrm{~min}$ at 

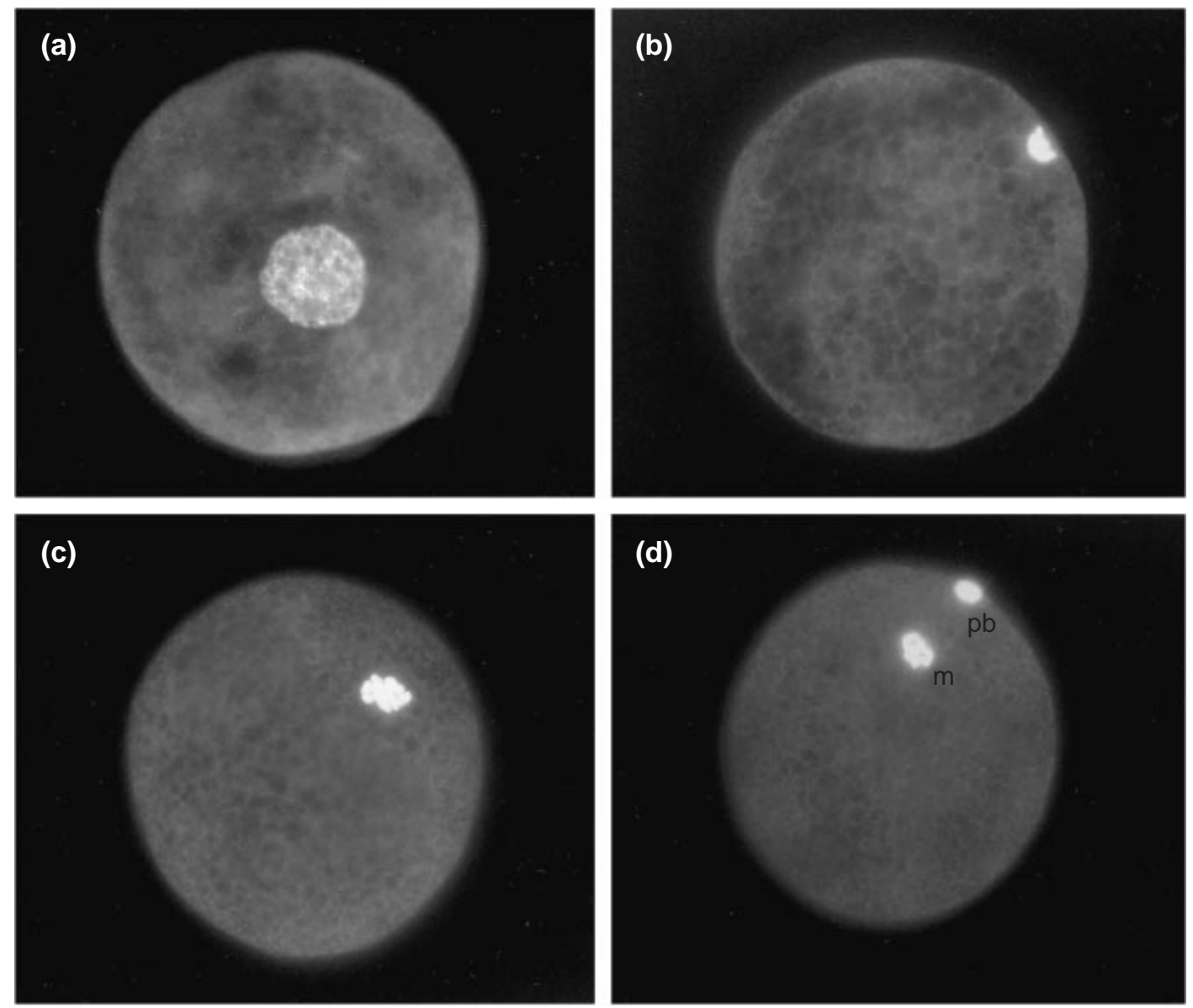

Fig. 1. Chromatin configurations in canine oocytes. (a) germinal vesicle; (b) condensed chromatin; (c) metaphase I; (d) metaphase II (m) and polar body (pb). Magnification is $\times 200$.

room temperature. The oocytes were transferred into the small drop comprising PBS supplemented with $90 \%(\mathrm{v} / \mathrm{v})$ glycerol (Sigma) and $1.9 \mu \mathrm{mol}$ bis-benzimide $\mathrm{I}^{-1}$ (Hoechst 33342, Sigma) on a slide. Subsequently, the oocytes were overlaid with a coverslip supported by four droplets of vaseline/paraffin and incubated overnight at $4^{\circ} \mathrm{C}$. The oocytes were examined using a fluorescence microscope with a $355 \mathrm{~nm}$ wavelength excitation filter and classified according to chromatin configuration as 'germinal vesicle', 'condensed chromatin', 'metaphase I' or 'metaphase II' (Fig. 1). Those with diffusely stained cytoplasm characteristic of non-viable cells, and those in which chromatin was unidentifiable or not visible, were considered as degenerated.

\section{Statistical analysis}

Each experiment was repeated five to seven times. The percentages of oocytes reaching each stage of meiosis after maturation culture were subjected to arc sin transformation before analysis, and then were tested by a post hoc, Fisher's protected least significant difference test (PLSD test).
Differences at $P \leqslant 0.05$ were considered significant. Data are expressed as means \pm SEM.

\section{Results}

\section{Experiment 1}

The effect of the incubation number of COCs collected from ovaries at anoestrus and dioestrus on meiotic competence of oocytes cultured in $100 \mu \mathrm{l}$ drop of the maturation medium are shown (Table 1). All oocytes were fixed and stained after culture for $72 \mathrm{~h}$, of which $6.2 \%$ (27 of 435 ) and $4.9 \%$ (25 of 510 ) of oocytes from ovaries at anoestrus (19 pairs) and dioestrus (28 pairs) were lost during fixation and staining, respectively, and the remaining oocytes were analysed for nuclear maturation. In the anoestrous group, the number of COCs incubated affected the meiotic competence of oocytes. When ten COCs were cultured in $100 \mu \mathrm{l}$ drops of the maturation medium, a significantly lower proportion of oocytes remained at the germinal vesicle (GV) stage, compared with groups in which 15 or 20 COCs were cultured $(P<0.05)$. Moreover, 
Table 1. Meiotic maturation of canine oocytes cultured for $72 \mathrm{~h}$ in $100 \mu \mathrm{l}$ drop

\begin{tabular}{|c|c|c|c|c|c|c|c|}
\hline \multirow{2}{*}{$\begin{array}{l}\text { Stage of } \\
\text { oestrous } \\
\text { cycle }\end{array}$} & \multirow{2}{*}{$\begin{array}{l}\text { Number of } \\
\text { oocytes cultured } \\
\text { (per } 100 \mu \mathrm{l})\end{array}$} & \multirow{2}{*}{$\begin{array}{l}\text { Number of } \\
\text { oocytes } \\
\text { examined* }\end{array}$} & \multicolumn{4}{|c|}{ Mean \pm SEM of oocytes at stage } & \multirow[b]{2}{*}{ Degenerated } \\
\hline & & & GV & $\mathrm{CC}$ & MI & $\mathrm{MII}^{+}$ & \\
\hline \multirow[t]{5}{*}{ Anoestrus } & 5 & 96 & $59.3 \pm 5.2^{a, b}$ & $6.9 \pm 3.1^{\mathrm{a}, \mathrm{b}}$ & $16.2 \pm 2.8^{\mathrm{a}}$ & $4.6 \pm 1.9^{a}$ & $13.1 \pm 4.5^{\mathrm{a}, \mathrm{b}}$ \\
\hline & 10 & 121 & $50.1 \pm 6.3^{\mathrm{a}}$ & $10.9 \pm 3.0^{\mathrm{a}}$ & $4.7 \pm 2.9^{b, c}$ & $16.2 \pm 4.5^{b}$ & $18.1 \pm 4.1^{\mathrm{a}, \mathrm{b}}$ \\
\hline & 15 & 92 & $72.5 \pm 3.8^{\mathrm{b}, \mathrm{c}}$ & $6.9 \pm 2.6^{a, b}$ & $6.0 \pm 0.9^{a, b}$ & $5.6 \pm 1.9^{a, b}$ & $9.0 \pm 5.3^{a, b}$ \\
\hline & 20 & 99 & $84.7 \pm 2.0^{c}$ & $2.5 \pm 1.5^{\mathrm{b}}$ & $1.7 \pm 1.1^{b}$ & $7.0 \pm 2.5^{\mathrm{a}, \mathrm{b}}$ & $4.0 \pm 1.4^{\mathrm{a}}$ \\
\hline & Total & 408 & $65.3 \pm 3.9^{\mathrm{A}}$ & $7.0 \pm 1.4$ & $7.5 \pm 1.7$ & $8.6 \pm 1.8$ & $11.5 \pm 2.3^{\mathrm{A}}$ \\
\hline \multirow[t]{5}{*}{ Dioestrus } & 5 & 132 & $46.4 \pm 7.9^{a}$ & $10.9 \pm 1.7^{a}$ & $7.9 \pm 1.5^{\mathrm{a}, \mathrm{b}}$ & $5.6 \pm 1.2^{\mathrm{a}}$ & $29.2 \pm 8.9^{b}$ \\
\hline & 10 & 119 & $49.4 \pm 2.6^{\mathrm{a}}$ & $8.7 \pm 2.0^{a, b}$ & $5.8 \pm 3.0^{\mathrm{b}, \mathrm{c}}$ & $10.4 \pm 5.5^{\mathrm{a}, \mathrm{b}}$ & $25.7 \pm 6.5^{a, b}$ \\
\hline & 15 & 131 & $39.3 \pm 10.1^{\mathrm{a}}$ & $6.7 \pm 2.7^{\mathrm{a}, \mathrm{b}}$ & $12.3 \pm 4.3^{\mathrm{a}, \mathrm{c}}$ & $11.3 \pm 4.0^{\mathrm{a}, \mathrm{b}}$ & $30.3 \pm 10.7^{b}$ \\
\hline & 20 & 103 & $50.2 \pm 10.4^{a}$ & $7.7 \pm 1.6^{a, b}$ & $13.7 \pm 5.6^{\mathrm{a}, \mathrm{c}}$ & $2.2 \pm 1.3^{\mathrm{a}}$ & $26.3 \pm 11.9^{a, b}$ \\
\hline & Total & 485 & $46.1 \pm 3.9^{\mathrm{B}}$ & $8.5 \pm 1.0$ & $9.8 \pm 1.9$ & $7.6 \pm 1.9$ & $28.0 \pm 4.4^{\mathrm{B}}$ \\
\hline
\end{tabular}

GV: germinal vesicle; CC: condensed chromatin; MI: metaphase I; MII: metaphase II.

*Of the oocytes examined in each group, 1-17 oocytes were lost during removal of cumulus cells, fixation and staining.

'The MII oocytes had metaphase chromosomes and polar body.

a-c, A-B Values with different superscripts in the same column differ significantly $(P<0.05)$.

Table 2. Meiotic maturation of canine oocytes cultured for $72 \mathrm{~h}$ by suitable oocyte density according to the reproductive cycle of the donor

\begin{tabular}{|c|c|c|c|c|c|c|c|c|}
\hline \multirow{2}{*}{$\begin{array}{l}\text { Stage of } \\
\text { oestrous } \\
\text { cycle }\end{array}$} & \multirow{2}{*}{$\begin{array}{c}\text { Number of } \\
\text { oocytes } \\
\text { cultured }\end{array}$} & \multirow{2}{*}{$\begin{array}{l}\text { Volume of } \\
\text { medium } \\
(\mu \mathrm{l})\end{array}$} & \multirow{2}{*}{$\begin{array}{l}\text { Number of } \\
\text { oocytes } \\
\text { examined* }\end{array}$} & \multicolumn{4}{|c|}{ Mean \pm SEM of oocytes at stage } & \multirow[b]{2}{*}{ Degenerated } \\
\hline & & & & GV & $\mathrm{CC}$ & MI & $\mathrm{MII}^{+}$ & \\
\hline \multirow[t]{4}{*}{ Anoestrus } & 1 & 10 & 85 & $48.1 \pm 3.4$ & $7.9 \pm 3.3$ & $21.2 \pm 7.4^{\mathrm{a}}$ & $7.0 \pm 3.3$ & $15.9 \pm 4.5$ \\
\hline & 5 & 50 & 109 & $48.5 \pm 5.9$ & $9.2 \pm 3.3$ & $12.2 \pm 2.0^{a, b}$ & $5.3 \pm 1.6$ & $24.8 \pm 2.5$ \\
\hline & 10 & 100 & 104 & $45.6 \pm 9.7$ & $9.9 \pm 4.0$ & $6.1 \pm 2.2^{b}$ & $10.4 \pm 4.9$ & $28.1 \pm 4.8$ \\
\hline & Total & & 298 & $47.3 \pm 3.8$ & $9.0 \pm 2.0$ & $13.2 \pm 3.1$ & $7.7 \pm 2.1$ & $22.8 \pm 2.6$ \\
\hline \multirow[t]{4}{*}{ Dioestrus } & 1 & 7 & 112 & $52.6 \pm 9.1$ & $6.2 \pm 1.3$ & $10.4 \pm 1.6^{\mathrm{a}, \mathrm{b}}$ & $11.5 \pm 3.7$ & $19.2 \pm 10.3$ \\
\hline & 5 & 35 & 92 & $44.9 \pm 8.7$ & $6.0 \pm 1.0$ & $11.0 \pm 4.0^{\mathrm{a}, \mathrm{b}}$ & $9.9 \pm 2.9$ & $28.2 \pm 10.9$ \\
\hline & 15 & 105 & 88 & $68.3 \pm 6.5$ & $3.4 \pm 0.1$ & $6.8 \pm 3.4^{\mathrm{a}, \mathrm{b}}$ & $11.3 \pm 5.9$ & $10.2 \pm 2.0$ \\
\hline & Total & & 292 & $53.3 \pm 5.4$ & $5.5 \pm 0.7$ & $9.8 \pm 1.7$ & $10.9 \pm 2.0$ & $20.6 \pm 5.7$ \\
\hline
\end{tabular}

GV: germinal vesicle; CC: condensed chromatin; MI: metaphase I; MII: metaphase II.

${ }^{*}$ Of the oocytes examined in each group, 2-8 oocytes were lost during removal of cumulus cells, fixation and staining.

the MII oocytes had metaphase chromosome and polar body.

$\mathrm{a}, \mathrm{b}$ Values with different superscripts in the same column differ significantly $(P<0.05)$.

significantly more oocytes reached metaphase II in the group cultured with 10 COCs than in the group cultured with 5 COCs $(P<0.05)$. In contrast, there were no effects of the incubation number of COCs on the meiotic competence of oocytes collected from ovaries at dioestrus. However, the proportion of oocytes that reached at least metaphase I tended to increase in the group cultured with 15 COCs, compared with other groups. When the data for the four different incubation numbers of COCs were combined to investigate any effect of the oestrous cycle stage of the ovary, the percentage of oocytes that remained at the GV stage was significantly lower in the dioestrous group than in the anoestrous group $(46.1 \%$ versus $65.3 \%, P<0.01)$.
However, the degeneration rate of oocytes from ovaries at the dioestrous stage significantly increased, compared with that of oocytes at the anoestrous stage $(28.0 \%$ versus $11.5 \%, P<0.01)$. There were no significant differences between the anoestrous and dioestrous groups with respect to the proportion of oocytes reaching metaphase II $(8.6 \%$ versus $7.6 \%$ ).

\section{Experiment 2}

The effect of culturing COCs singly or in different group sizes on meiotic competence of oocytes cultured in a drop of maturation medium at the fixed ratio of oocyte density 
according to the stage of the reproductive cycle of the donor is shown (Table 2). All oocytes were fixed and stained after culture for $72 \mathrm{~h}$, of which $5.4 \%$ (17 of 315 ) and $5.8 \%$ (18 of 310 ) of oocytes from ovaries at anoestrus (14 pairs) and dioestrus (18 pairs) were lost during fixation and staining, respectively. In the anoestrous group, the proportion of oocytes that remained at metaphase I was lower in the group cultured with 10 COCs than in the single-cultured group. However, there were no differences in the proportions of oocytes reaching metaphase II among the different group sizes in each stage of the reproductive cycle of the donor. In comparison with the combined data for the three different incubation numbers of COCs in each oestrous cycle of ovary, there were no significant differences between the anoestrous and dioestrous groups with respect to the proportions of oocytes reaching each meiotic stage.

\section{Discussion}

The results of the present study show that oocyte density (number per unit volume) influences the meiotic resumption of oocytes collected from ovaries at anoestrus, but has no apparent effects on the meiotic resumption of oocytes at dioestrus. Even though many studies have been published regarding the meiotic ability of canine oocytes, none has provided data about the oocyte density to medium volume. Petr et al. (1989) reported that the incidence of germinal vesicle breakdown (GVBD) decreases with increasing numbers of pig COCs cultured in a drop. Similarly, increasing the number of bovine COCs to a small drop resulted in a significant inhibition of meiotic competence (Sirard et al., 1992). It has been proposed that the factors inhibiting GVBD are produced by the cumulus cells and secreted into a culture medium (Isobe and Terada, 2001). Isobe and Terada (2001) suggested that the GVBDinhibiting factors inhibit the disruption of gap junctions, thus preventing oocytes from undergoing GVBD by continuous transfer of the inhibitor through the mediation of cumulus cells. It has been shown that a loss of communication between the oocyte and the granulosa cells via gap junctions is responsible for the resumption of oocyte meiotic maturation that occurs after the LH surge (Dekel and Beers, 1978; Gilula et al., 1978; Wert and Larsen, 1990). Wiesen and Midgley (1993) reported that only the granulosa cells of healthy and developing antral follicles express large amounts of connexin 43 gap junction mRNA, but very little connexin 43 gap junction mRNA was detected in the corpora lutea or in follicles undergoing atresia. They suggested that the expression of the gap junction gene is hormonally regulated during follicular growth and development. In the present study, an increase in the proportions of canine oocytes that remained at the GV stage was observed when a large number of COCs from ovaries at anoestrus were cultured in the same volume $(100 \mu \mathrm{l})$. At dioestrus, however, the quantitative influence of COCs on the meiotic resumption of oocytes was not observed under the same conditions. In the combined data, the percentage of oocytes that remained at the GV stage was significantly lower in the dioestrous group than in the anoestrous group, indicating that the number of COCs in which communication was lost between the oocyte and the cumulus cells via gap junctions might increase in the dioestrous group. Therefore, the differences in the quantitative effect of COCs on the meiotic resumption of oocytes between anoestrus and dioestrus may result from the differences of gap junctional communication that occur in the processes of follicular development. However, the degeneration rate of COCs was higher in the dioestrous group than in the anoestrous group. Studies in other species (mice, rats, pigs and cattle) have shown that some cumulusdenuded oocytes can complete meiotic resumption (Binor and Wolf, 1979; Magnusson, 1980; Yamauchi and Nagai, 1999; Geshi et al., 2000), but the removal of cumulus cells before oocyte maturation results in a significant reduction in the nuclear maturation rate (Das et al., 1997). The oocyte and the cells of cumulus and granulosa are interconnected by numerous gap junction channels that pass nucleotides, amino acids and sugars from the cells to the oocyte for growth and development (Zamboni, 1974; Eppig, 1979). Therefore, the increase in the degeneration rate of COCs at dioestrus may be related to the disruption of cumulusoocyte gap junctions.

The results of the present study show that there were no significant differences between the anoestrous and dioestrous groups with respect to the proportion of oocytes reaching metaphase II. This observation is consistent with a finding by Hewitt and England (1997) who reported that there were no differences in the maturation rates between oocytes collected from ovaries at anoestrus and dioestrus. However, the suitable oocyte density for reaching metaphase II was slightly different between the anoestrous and dioestrous groups in the present study. The oocytes were cultured for $72 \mathrm{~h}$ in the same culture medium, indicating that the culture of many COCs in a small amount of medium for a long time raises the possibility that nutrients for oocytes may be depleted from the medium. In contrast, the presence of supplementary granulosa cells during in vitro maturation of oocytes has been shown to exert beneficial effects (Fukui et al., 1991; Mochizuki et al., 1991). We previously reported that co-culture with bovine cumulus cells improved the rates of maturation of canine oocytes to metaphase II (Otoi et al., 2000b). It has been demonstrated that a significant amount of protein is accumulated in cumulus cells and secreted during oocyte maturation (Rabahi et al., 1991; Wu et al., 1996). Parrott and Skinner (1999) suggested that the paracrine factors secreted by granulosa cells promote germ cell survival and oocyte growth in cell culture systems. Moreover, the cumulus or granulosa cells act as scavengers, that is, they remove toxic materials from the culture medium (Khurana and Niemann, 2000). Therefore, the difference of suitable oocyte density between the anoestrous and dioestrous groups may indicate that the number of cumulus cells in 
COCs that reached the critical level required to ensure full meiotic maturation is slightly different between groups.

In bitches, most studies on IVM have been carried out on group cultures, but the meiotic competence of oocytes cultured singly or in small groups has not been determined. In practice, the culture of canine oocytes singly or in small groups is required, because the numbers of oocytes collected from individual ovaries vary greatly (Nickson et al., 1993; Fujii et al., 2000). In other mammals, it has been demonstrated that the rate of embryo development is density dependent, with single oocyte cultures resulting in inferior rates of development compared with group cultures in drops of the same volume (Lane and Gardner, 1992; Gardner et al., 1994). The developmental competence was improved by culturing embryos in reduced volumes (Lane and Gardner, 1992; Gardner et al., 1994; Kato and Tsunoda, 1994). However, there appears to be little information on the IVM of oocytes cultured singly or in small groups. Fukui et al. (2000) reported that the proportions of bovine oocytes that reached metaphase II were not different with regard to the single and group culture in drops of the same volume. In the present study, when canine oocytes were cultured at suitable oocyte density according to the reproductive cycle of the donor, there were no differences in the proportions of oocytes reaching metaphase II among the different group sizes, irrespective of the oestrous cycles of ovaries. Therefore, the present results indicate that the group sizes have no effect on the meiotic competence of oocytes cultured at suitable oocyte density.

Most studies of IVM in bitches have used standard culture techniques using culture media such as TCM199 and Krebs-Ringer bicarbonate solution with or without serum or hormonal supplementation (Yamada et al., 1992; Nickson et al., 1993; Hewitt and England, 1999; Otoi et al., 1999; Saint-Dizier et al., 2001). However, the completion of meiosis obtained in these studies was low, and less than $40 \%$ of cultured oocytes reached metaphase II. Songsasen et al. (2002) reported that addition of growth hormone or $\beta$-mercaptoethanol to maturation medium did not improve nuclear maturation of canine oocytes, and a high concentration of glucose in the medium had a detrimental effect on meiotic maturation of the oocytes. In the present study, the average percentage of oocytes reaching metaphase II was very low $(<11 \%)$, irrespective of oocyte source and culture method. Therefore, further study will be required to determine the culture requirements of canine oocytes for completion of meiotic maturation.

In conclusion, the present study indicates that the influence of oocyte density on the meiotic competence of canine oocytes differs according to the oestrous cycle stage of the donor, but the oocyte cultured singly at suitable oocyte density during IVM can be matured to a similar stage to oocytes cultured in groups, irrespective of the oocyte source.

The authors would like to thank the staff of their laboratory for help with sample collection. This work was supported by the Missyplicity project.

\section{References}

Binor Z and Wolf DP (1979) In vitro maturation and penetration of mouse primary oocytes after removal of the zona pellucida Journal of Reproduction and Fertility $\mathbf{5 6}$ 309-314

Carolan C, Lonergan P, Khatir H and Mermillod P (1996) In vitro production of bovine embryos using individual oocytes Molecular Reproduction and Development 45 145-150

Das SK, Chauhan MS, Palta P and Tomer OS (1997) Influence of cumulus cells on in vitro maturation of denuded buffalo oocytes Veterinary Record $141522-523$

Dekel N and Beers WH (1978) Rat oocyte maturation in vitro: relief of cyclic AMP inhibition by gonadotropins Proceedings National Academy of Sciences USA 75 4369-4373

Eppig JJ (1979) A comparison between oocyte growth in coculture with granulosa cells and oocyte with granulosa cell-oocyte junctional contact maintained in vitro. Journal of Experimental Zoology 209 345-353

Farstad W (2000) Assisted reproductive technology in canid species Theriogenology 53 175-186

Fujii M, Otoi T, Murakami M, Tanaka M, Une S and Suzuki T (2000) The quality and maturation of bitch oocytes recovered from ovaries by the slicing method Journal of Veterinary Medical Science 62 305-307

Fukui Y, MacGowan LT, James RW, Pugh PA and Tervit HR (1991) Factors affecting the in vitro development to blastocysts of bovine oocytes matured and fertilized in vitro. Journal of Reproduction and Fertility 92 125-131

Fukui Y, Kikuchi Y, Kondo H and Mizushima S (2000) Fertilizability and developmental capacity of individually cultured bovine oocytes Theriogenology 53 1553-1565

Funahashi H, Cantley T and Day BN (1994) Different hormonal requirements of pig oocyte-cumulus complexes during maturation in vitro. Journal of Reproduction and Fertility 101 159-165

Gardner DK, Lane M, Spitzer A and Batt PA (1994) Enhanced rates of cleavage and development for sheep zygotes cultured to the blastocyst stage in vitro in the absence of serum and somatic cells: amino acids, vitamins, and culturing embryos in groups stimulate development Biology of Reproduction 50 390-400

Geshi M, Takenouchi N, Yamauchi N and Nagai T (2000) Effects of sodium pyruvate in nonserum maturation medium on maturation, fertilization, and subsequent development of bovine oocytes with or without cumulus cells Biology of Reproduction 63 1730-1734

Gilula NB, Epstein ML and Beers WH (1978) Cell-to-cell communication and ovulation. A study of the cumulus-oocyte complex Journal of Cell Biology 78 58-75

Hewitt DA and England GCW (1997) Effect of preovulatory endocrine events upon maturation of oocytes of domestic bitches Journal of Reproduction and Fertility Supplement 51 83-91

Hewitt DA and England GCW (1998) The effect of oocyte size and bitch age upon oocyte nuclear maturation in vitro. Theriogenology 49 957-966

Hewitt DA and England GCW (1999) Influence of gonadotrophin supplementation on the in vitro maturation of bitch oocytes Veterinary Record 144 237-239

Hewitt DA, Watson PF and England GCW (1998) Nuclear staining and culture requirements for in vitro maturation of domestic bitch oocytes Theriogenology 49 1083-1101

Isobe $\mathbf{N}$ and Terada T (2001) Effect of the factor inhibiting germinal vesicle breakdown on the disruption of gap junctions and cumulus expansion of pig cumulus-oocyte complexes cultured in vitro. Reproduction 121 249-257

Kato Y and Tsunoda Y (1994) Effects of the culture density of mouse zygotes on the development in vitro and in vivo. Theriogenology 41 1315-1322

Khurana NK and Niemann H (2000) Effects of oocyte quality, oxygen tension, embryo density, cumulus cells and energy substrates on cleavage and morula/blastocyst formation of bovine embryos Theriogenology 54 $741-756$

Kito S, Iritani A and Bavister BD (1997) Effects of volume, culture media and type of culture dish on in vitro development of hamster 1-cell embryos Theriogenology 47 541-548 
Lane M and Gardner DK (1992) Effect of incubation volume and embryo density on the development and viability of mouse embryos in vitro. Human Reproduction 7 558-562

Magnusson C (1980) Role of cumulus cells for rat oocyte maturation and metabolism Gamete Research 3 133-140

Mahi CA and Yanagimachi R (1976) Maturation and sperm penetration of canine ovarian oocytes in vitro. Journal of Experimental Zoology 196 189-196

Mochizuki H, Fukui Y and Ono H (1991) Effect of the number of granulosa cells added to culture medium for in vitro maturation, fertilization and development of bovine oocytes Theriogenology 36 973-986

Nickson DA, Boyd JS, Eckersall PD, Ferguson JM, Harvey MJA and Renton JP (1993) Molecular biological methods for monitoring oocyte maturation and in vitro fertilization in bitches Journal of Reproduction and Fertility Supplement 47 231-240

Otoi T, Fujii M, Tanaka M, Ooka A and Suzuki T (1999) Effect of serum on the in vitro maturation of canine oocytes Reproduction, Fertility and Development 11 387-390

Otoi T, Fujii M, Tanaka M, Ooka A and Suzuki T (2000a) Canine oocyte diameter in relation to meiotic competence and sperm penetration Theriogenology 54 535-542

Otoi T, Murakami M, Fujii M, Tanaka M, Ooka A, Une S and Suzuki T (2000b) Development of canine oocytes matured and fertilised in vitro. Veterinary Record 146 52-53

Otoi T, Ooka A, Murakami M, Karja NW and Suzuki T (2001) Size distribution and meiotic competence of oocytes obtained from bitch ovaries at various stages of the oestrous cycle Reproduction, Fertility and Development 13 151-155

Parrott JA and Skinner MK (1999) Kit-ligand/stem cell factor induces primordial follicle development and initiates folliculogenesis Endocrinology 140 4262-4271

Petr J, Zetova L, Fulka JJ and Jilek F (1989) Quantitative inhibitory influence of porcine cumulus cells upon the maturation of pig and cattle oocyte in vitro. Reproduction Nutrition Development 29 541-550

Rabahi F, Monniaux D, Pisselet C, Chupin D and Durand P (1991) Qualitative and quantitative changes in protein synthesis of bovine follicular cells during the preovulatory period Molecular Reproduction and Development 30 265-274

Saint-Dizier M, Renard JP and Chastant-Maillard S (2001) Induction of final maturation by sperm penetration in canine oocytes Reproduction 121 97-105

Sirard MA, Coenen K and Bilodeau S (1992) Effect of fresh or cultured follicular fractions on meiotic resumption in bovine oocytes Theriogenology 37 39-57

Songsasen N, Yu I and Leibo SP (2002) Nuclear maturation of canine oocytes cultured in protein-free media Molecular Reproduction and Development 62 407-415

Theiss T (1997) Investigations on the Collection, In Vitro Maturation and Fertilization of Dog Oocytes PhD Thesis, Tierartzliche Fakultat der Ludwig-Maximillian Universitat Munich

Wert SE and Larsen WJ (1990) Pre-endocytotic alterations in cumulus cell gap junctions precede meiotic resumption in the rat cumulus-oocyte complex Tissue and Cell 22 827-851

Wiesen JF and Midgley ARJ (1993) Changes in expression of connexin 43 gap junction messenger ribonucleic acid and protein during ovarian follicular growth Endocrinology 133 741-746

Wu B, Ignotz GG, Currie WB and Yang X (1996) Temporal distinctions in the synthesis and accumulation of proteins by oocytes and cumulus cells during maturation in vitro of bovine oocytes Molecular Reproduction and Development 45 560-565

Yamada S, Shimazu Y, Kawaji H, Nakazawa M, Naito K and Toyoda Y (1992) Maturation, fertilization and development of dog oocytes in vitro. Biology of Reproduction 46 853-858

Yamada S, Shimazu Y, Kawano Y, Nakazawa M, Naito K and Toyoda Y (1993) In vitro maturation and fertilization of preovulatory dog oocytes Journal of Reproduction and Fertility Supplement 47 227-229

Yamauchi $\mathbf{N}$ and Nagai T (1999) Male pronuclear formation in denuded porcine oocytes after in vitro maturation in the presence of cysteamine Biology of Reproduction $\mathbf{6 1} 828-833$

Zamboni L (1974) Fine morphology of the follicle wall and follicle cell-oocyte association Biology of Reproduction 10 125-149

Received 22 March 2002.

First decision 7 August 2002.

Revised manuscript received 9 September 2002.

Accepted 9 September 2002. 